Igor BIZJAK

\section{Principles and applications of knowledge management for the BC industry (with examples)}

\section{Introduction}

T. D.Wilson professor emeritus of University of Sheffield, UK wrote in The Information Research an article "The nonsense of knowledge management « (Wilson, T.D., 2002). In his article T. D.Wilson asks himself what is the difference between knowledge and information and what the definition "knowledge management « might be. So he made a research on the »knowledge management « appearances through various citation indexes from 1981 to 2002, articles, books, schools and even some research on so called »tacit knowledge «.

In most cases the authors were using "knowledge « simply as a synonym for »information «. In other cases the »knowledge management tool « is nothing but the information about the intellectual resources of a firm. Or they want to re-sell expert systems under a new label. In some cases "knowledge resources « turn out to be information resources and so on.

His conclusion was:

"The inescapable conclusion of this analysis of the žknowledge management' idea is that it is, in large part, a management fad, promulgated mainly by certain consultancy companies, and the probability is that it will fade away like previous fads. It rests on two foundations: the management of information - where a large part of the fad exists (and where the žsearch and replace marketing' phenomenon is found), and the effective management of work practices. However, these latter practices are predicated upon a Utopian idea of organizational culture in which the benefits of information exchange are shared by all, where individuals are given autonomy in the development of their expertise, and where žcommunities' within the organization can determine how that expertise will be used. Sadly, we are a long way removed from that Utopia: whatever businesses claim about people being their most important resource, they are never reluctant to rid themselves of that resource (and the knowledge it possesses) when market conditions decline. In the U.K. we can point to British Airways, which, in the aftermath of the terrorist attack of the 11th September 2001, paid off more than 7,000 of its žknowledge resources' - financial observers suggested that they were simply waiting for a suitable excuse to do so, management having taken disastrous business decisions which had reduced profitability. We can also point to Barclays Bank, with profits of more than £2 billion in 2001 and profit growth that year of almost $3.0 \%$, which, nevertheless, paid off some $10 \%$ of its total global workforce. No imagination appears to have been used by either of these companies to determine ways in which their žmost important resource' might be more effectively employed to increase turnover and profits. «
So, is the term »knowledge management « just another word for information gathering or it is just a commercial term for boosting the economy in the field, because the »knowledge management « is popular that particular moment? His view on the matter is really more cynical. But can we say that information is knowledge or the writers who wrote such articles cannot distinguished between information and knowledge? Or that "knowledge management « is no more than some sort of gathering, organizing, storing and retrieving the information. What exactly is "knowledge management« then?

\section{What is Knowledge Management?}

If one asked Google, one would receive about 20 different explanations of the term »knowledge management « in English. They are:

- Capturing, organizing, and storing knowledge and experiences of individual workers and groups within an organization and making this information available to others in the organization. (from

[library.ahima.org/xpedio/groups/public/ documents/ahima/pub_bok1_025042.html])

- Knowledge management is the name of a concept in which a company or organization consciously and comprehensively gathers, organizes, shares, and analyzes its knowledge in terms of resources, documents, and people skills.

(from [eec.lboro.ac.uk/learningtech/jtor.htm])

- A method for gathering information and making it available to others. (from

[www.qualishealth.org/qi/collaboratives/glossary.cfm])

- The way a company stores, organizes and accesses internal and external information. Narrower terms are: "Organizational Memory" and "Knowledge Transfer. " (Process) (from [ccs.mit.edu/21c/iokey.html])

- the collection, organization, analysis, and sharing of information held by workers and groups within an organization. (from [www.worldwidelearn.com/ elearning-essentials/elearning-glossary.htm])

- The process of systematically and actively managing and leveraging the stores of knowledge in an organisation is called knowledge management. It is the process of transforming information and intellectual assets into enduring value. (from [www.unisa.edu.au/pas/qap/planning/ glossary.asp])

- A system or framework for managing the organizational processes that create, store and distribute knowledge, as defined by its collective data, information and body of experience. (from [www.bridgefieldgroup.com/glos5.htm])

- A business process that formalizes management and leverage of a firm's intellectual assets. KM is an enterprise discipline that promotes a collaborative and integrative approach to the creation, capture, organization, access and use of information assets, including the tacit, uncaptured knowledge of people. (from [www.business-resources.net/glossary/])

- A multi-disciplined approach to achieving organisational objectives by making best use of knowledge. It involves the design, review and implementation of both social and technological processes to improve the application of knowledge, in the collective interest of stakeholders. AS 5037 Clause 1.2.4 (from [www.records.nsw.gov.au/ publicsector/rk/glossary/singleversion.htm])

- is a process for optimizing the effective application of intellectual capital to achieve objectives. In an organizatio- 
nal setting, this would mean a systematic approach to getting an organization to make the best possible use of knowledge in implementing its mission, broadly viewed as either sustainable competitive advantage or long-term high performance. ...

(from [www.mountainquestinstitute.com/definitions.htm])

- We believe true Knowledge Management is eliciting and sharing the experience and intelligence of everyone working in a particular process.

(from [www.phredsolutions.com/glossary.html])

- Strategic policy setting and information principles for Digital Asset Management (DAM), Document Management (DM), Content Management (CM), Web Content Management (WCM) and Records Management (RM).

(from [www.intellectuk.org/sectors/ document_management/glossary.asp])

- Discipline within an organisation that ensures that the intellectual capabilities of an organisation are shared, maintained and institutionalised. (from

[www.dream-catchers-inc.com/White\%20Papers/ glossary_of_terms-AM.htm])

- This still-evolving concept involves harnessing enterprise wide data, proprietary or otherwise, for comparative decision-making, workflow automation, supply chain management, and/or competitive advantage. Far more than information-aggregation, knowledge management seeks to enhance business value and help employees work more productively. (from [www.payorid.com/glossary.asp])

- The strategic use of information and knowledge resources to an organization «s best advantage.

(from [www.gov.bc.ca/prem/popt/service_plans/ srv_pln/pssg/appen_a.htm])

- is the industry buzzword used to describe a set of tools for capturing and reuse of knowledge.

(from [www.functionalknowledge.com/glossary.html])

- The process of creating, capturing, and using knowledge to enhance organizational performance. Knowledge management is most frequently associated with two types of activities. One is to document and appropriate individuals' knowledge and then disseminate it through such venues as a companywide database. Knowledge management also includes activities that facilitate human exchanges using such tools as groupware, email, and the Internet. (from [www.astd.org/astd/Resources/ performance_improvement_community/Glossary.htm])

- Knowledge management (KM) is the organization, creation, sharing and flow of knowledge within organizations. (from [en.wikipedia.org/wiki/Knowledge_management])

There are also several definitions in the Slovene language:

- "Knowledge management is a business process one can manage intellectual assets of an organization with. (Slak, M. 2002)

- "Knowledge management « is a part of human capital portfolio in which companies must invest and constantly take care of. (Drakulič, I. 2004)

One can summarise that "knowledge « involves mental processes in one's mind. These processes are comprehension, understanding and learning. And »management « of »knowledge " on the other hand are activities to gather, store, organize and share that »knowledge « so that organization that collects such »knowledge « can benefit from it.

One must distinguish knowledge from data and information (Zack, M. H., 1999). Data represents just pure facts or observations, not directly connected to anything.
Information on the other hand results from placing data in some context and making the data meaningful. The information can be in a form of a message. Knowledge are those messages that one accumulates and meaningfully organizes through experience, communication or inference. Knowledge can be viewed both as a thing to be stored and manipulated and as a process of simultaneously knowing and acting - that is, applying expertise.

So "knowledge « involves mental processes of comprehension (Wilson, T.D., 2002), understanding and learning that go on in the mind and only in the mind. However they can involve interaction with the world outside the mind, and interaction with others. One can express what one knows, by uttering messages of one kind or another - oral, written, graphic, gestural or even through žbody language'. Such messages do not carry »knowledge «, they constitute »information «, which a knowing mind may assimilate, understand, comprehend and incorporate into its own knowledge structures.

"Knowledge « can be tacit or explicit (Zack, M. H., 1999). Explicit is very precise and formally articulated. Because of that it can be easily codified, documented, shared or manipulated. In organization it can be in a form of procedure manuals, product literature or even in a form of computer software. On the other hand tacit knowledge is developed from direct experience and action, shared through story-telling, shared experience and interactive conversation. It is subconsciously understood and applied and difficult to articulate.

Tacit knowledge by Wilson (Wilson, T.D., 2002) involves the process of comprehension, a process which is, by itself, poorly understood. Consequently, tacit knowledge is an inexpressible process that enables an assessment of phenomena in the course of becoming knowledgeable about the world.

When organization "captures « knowledge it has to manage it or the acquired knowledge will eventually be lost. Knowledge management can be described in many ways as mentioned earlier in the paper. Different organizations understand it differently. For instance U.S. Department of transportations, defines it as "the process of capturing and sharing a community's collective expertise to fulfil its mission. Knowledge management takes advantage of an organization's most valuable asset - the collective expertise of its employees and partners (Burk, M., 1999). Most organisations involved in knowledge management think that way. Many organizations are not aware of the knowledge possesed by the employees and if an organization wants to explore and harvest that knowledge it should know how.

Knowledge management acts something like a library. It provides a repository for written information on a given subject, but it also tries to make it available to the organization as a whole. The knowledge that is in man's mind may be the most valuable of all because it is put in context and it is frequently more extensive and up-to-date and, therefore, more useful for decision-making. In short, knowledge management helps ensure that the right information gets to the right people at the right time to make the right decision (Burk, M., 1999).

As mentioned earlier the knowledge must be first found or created. This can be done by conferences and meetings, by sharing experience through workshops, seminars, projects and research. The next step would be to organize that know- 
ledge. That task could be done by a person called knowledge manager. The knowledge manager would catalogue and sort every new information that comes into the organization and will also help everyone in that organization to find the needed information. So the knowledge manager would share knowledge with others so that the others could use that knowledge and obtain new knowledge. So the process could start again. That is called the knowledge cycle.

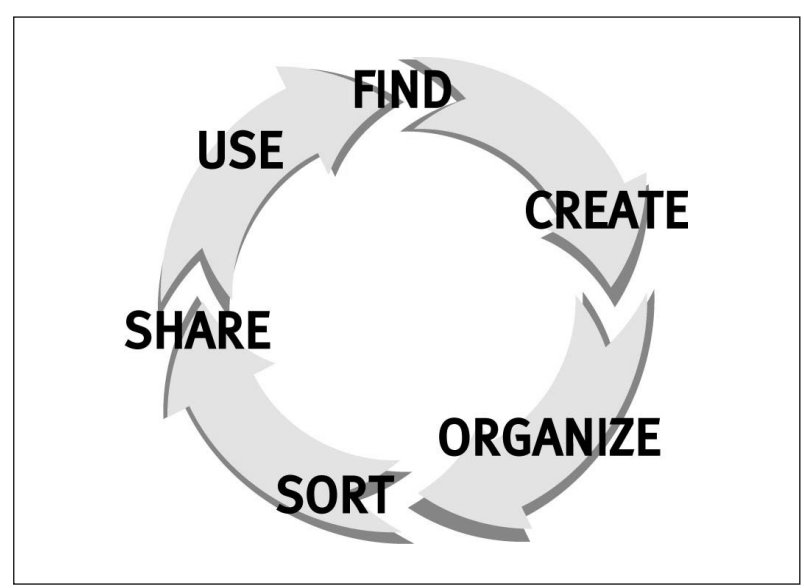

Figure 1: Knowledge cycle (BIZJAK I., 2006)

\section{Examples of Knowledge Management in the $\mathrm{BC}$ industry}

How can BC industry use »knowledge management«? The knowledge is made by people that are inside organizations. So the logic answer would be that it can be used through employees and that employees are the most valuable asset of any organization. The knowledge must be managed and who could do this best but the assigned people, so called "knowledge managers " or in a case of bigger organizations expert centres or even organizations specialized in knowledge management.

Their responsibilities typically include championing knowledge management, educating the organization, knowledge mapping, and integrating the organizational and technological resources comprising the knowledge management architecture. Additionally, explicit responsibility should be assigned for each stage of refinery and interfaces between them. Assigning responsibility for a seamless transition of knowledge from acquisition to use, as well as interfaces between these stages, all would help ensure that knowledge repositories will be meaningfully created and effectively used (Zack, M. H., 1999).

Information technologies provide the organizations with means for capturing, cataloguing, storing, sorting, searching and presenting knowledge. The technologies as world wide web, Lotus Notes, SharePoint Portal etc. are some examples of technologies that can manage such tasks. Knowledge processing can be segmented into two broad classes: integrative and interactive, each addressing different knowledge management objectives (Zack, M. H., 1999).

Integrative applications are built around knowledge repository. The repository is a primary medium for knowledge exchange and every user is either a producer or a consu- mer of knowledge and interacts with the repository rather than with each other. A consumer accepts the contents of the knowledge package that is produced through the repository. Such example would be an electronic newsletter, company documents, rules, policies, or directory of employees. On the other hand interactive applications are focused primarily for supporting interactions among people holding tacit knowledge. Here is the repository by product of such interaction rather the primary focus as in integrative applications. Electronic forums are such applications. In forums producers and consumers interact and the results is some sort of a repository filled with questions made by consumers and answers given by producers. The repository can be further linked to electronic publishing applications for editors to discuss the quality of the contributions, or to offer a place for readers to react to and discuss the publication.

Organizations in every field of industry are beginning to grasp the importance of »knowledge management «. This is also true in building and construction industry. There are many examples of usage of »knowledge management « in that field.

One such example is the e-COGNOS project. Its key issues are knowledge management in the construction domain and document interdependencies and consistency across projects and between enterprises.

The e-COGNOS platform presents the first comprehensive ontology-based portal for knowledge management in the construction domain. The main features of the platform are an ontology (to encapsulate human knowledge) and a set of web services to support the management of ontology (creation, updates), user management (profiling) and handling knowledge management requirements (indexing, documentation, retrieval and dissemination). Implementation of e-COGNOS platform (at leading European construction organizations) has proven the benefit of semantic systems as they provided adequate search and indexing capabilities, allowed for a systematic procedure for formally documenting and updating organizational knowledge (through the ontology) and enhanced the customization functions in a knowledge management systems (through user profiling). The development and implementation of the e-COGNOS platform has also shown that the managerial aspect of knowledge management (in terms of integrating knowledge in daily processes and the link between knowledge and organizational structure) is harder to attain. (C. Lima, Dr., et al., 2005)

In another example »An explorative study on knowledge management in the architectural practice « Isobel Chong tries to understand how knowledge is managed in a project-based, multi-profession environment. The research findings suggest that the main problems facing architectural practice are the management of tacit project knowledge. The inadequate management of tacit knowledge results in two inter-related problems: loss of project knowledge, and not knowing »who knows what «, which leads to »reinventing a wheel«. ( CHONG, I., 2002) The study case was an architectural firm from London. The firm was still in an early stage of a process to improve its knowledge management practice. In had three main types of knowledge that needed to be managed: first type is a specialist sector knowledge, second a profession (technical) knowledge, and the third one firm specific process knowledge. The firm 
uses technology mainly to manage explicit knowledge such as the firm specific process knowledge. The first two types were of tacit nature knowledge and thus difficult to manage. The study showed that by employing technology designed to facilitate the social networks and greater staff retention, the problem of managing tacit knowledge could be addressed.

There is another project of Dr.Lima, the so-called eConstruct IST project.

The eConstruct IST project has developed a communication technology called Building and Construction eXtensible mark-up Language (bcXM L), which provides the European Building and Construction industry with a powerful but low cost XML-based language that primarily supports the eBusiness communication needed between clients, architects, engineers, suppliers, and contractors for the procurement of products, components, and services. BcXML also handle multi-lingual issues required when a virtual construction enterprise operates over the borders of the individual European member states. In order to enable the bcXML communication language to be demonstrated and tested, the bc$X M L$ Reference Architecture was designed and a prototype demonstrator was implemented. A number of client applications have also been implemented within the prototype and demonstrated the proof of concept for bcXML. Moreover, $B c X M L$ has been adopted as the format to import taxonomies into the construction-oriented ontology that is developed in the IST e-COGNOS project, which is implementing a KM infrastructure tailored to the construction needs. This paper describes the bcXML Reference Architecture, the implemented prototype and how bcXML has been used in eCOGNOS. (C. Lima, Dr., et al., 2003)

In his paper »Next Generation Knowledge Management System for the Construction Industry « (CHRISTIANSSON, P., 2003) Per Christiansson explains the potential of new advanced ICT (Information and Communication Technology) and discusses how would these tools support and influence the building process models and its organisation. These tools are Basic XML language, Temporal databases and Semantic Web. The XML files produced as extracts from databases or other applications can be used to transfer data between building applications (databases, CAD programs, simulation programs, etc.). Temporal extension to traditional relational database systems can handle queries like "what resources have we used during different time periods of the conceptual design of the building? «, "who and what competencies were engaged during different time periods of the Virtual Building design? «, and "how many resources have we used over different time periods at different building locations? «. These types of questions are very difficult to handle in conventional databases, but can help capture experiences for better planning of resource allocation and to make complex time dependent queries. And Semantic Web can be build and make interoperable web based information containers with the use of XML based web services. The semantic web would allow users to introduce new services, to handle unstructured and structured data accessed from the internet. The services as link documents to other documents handling similar subjects/concepts; search specified and similar concepts in interaction with end user; annotate existing web contained documents; capture concepts in documents and create meta content descriptions; translate a document to another »language «; or combine low level concepts in different containers for idea generation.

\section{A Case of Practical Application of Knowledge Management (a casestudy) at the Urban Planning Institute of the Republic of Slovenia}

The Urban Planning Institute of the Republic of Slovenia is a public research organisation, recognised and partly financed by the Slovene government.

The mail fields of activities include methodology on programming urban development, methodology on shaping urban forming, urban geography and sociology, regional economics, applied demography with a regard to town-planning forecasting, comprehensive traffic studies, planning of residential areas, planning of tourist regions, urban renewal, preservation and landscape design, development of GIS, etc. Among objectives are advancement of theoretical research in planning and design, development and evaluation of planning methods and techniques, development and application of planning information systems, development of new activities related to institution building support, education and training of planning students and professionals, implementation of applied research in design projects, publishing, information exchange and documentation of planning literature, transfer of knowledge through consultation activities, etc.

In the field of professional development, the Institute elaborates model plans, standards, norms and planning criteria; it maintains a data-bank, provides information and documentation services; works on terminology and maintains a rich planning library. The Institute is involved in publishing and is educating design and planning professionals. In this way it is able to offer the public an insight into the theoretical and practical findings of its research staff and also a connection between domestic and foreign research and practice in the fields of urban and regional planning and design.

The Institute has 27 professionals working in research and on commissions and 9 in management, administration and support staff. In view of the trans-institutional policy of the Institute, professionals from other organisations are often invited as associates in the Institute's projects. Most of the employees of the Institute are fluent in at least one of the following languages: English, French, German, Italian, Russian, Spanish and the languages of the former Yugoslav republics. The structure of professionals are as follows: ten architects three with Ph.D., four landscape architects two with Ph.D. and one with M.A., four geographers one with Ph.D., two art historians both with Ph.D., one geodesist, one cultural sociologist with Ph.D., one sociologist with M.A., one agronomist, one economist with M.A., one mathematician and one ethnologist.

Upon internal structure the institute is divided into three groups. The main research group, which carried out all the research work, the infrastructure group, with the primary task as support for the research group, and with other tasks as care for various databases, to organize various trainings on the field of usage of new equipment (mainly computer software and hardware), to develop new software for the research group support etc. and administration group. Institute has its own library and information service, which specialised reference services offering literature and 
sources to students and professionals. Integrated into the national information-documentation system and through this into the international flow of information. On-line connection to host systems of the University in Ljubljana and University in Maribor enabling access to several international databases.

The institute has a lot of trained professionals with a lot of knowledge and tacit knowledge. All the research staff constantly undertake in research projects on the state level and also on the international level. They also participate in workshops and they present papers on the national and international conferences. Once a week they have the possibility to broaden their knowledge by taking part in weekly lectures on new computer software or new technology to use.

Every researcher upon finishing the research project is obligated to store a copy of the project in the library. Library then enters data on the project into Co-operative Online Bibliographic System \& Service (COBISS) database, and from there it is accessible to every one with an access to the internet. And about there every thing ends. So if anyone wants to learn about projects and materials other researchers did, the only way is to search through COBISS for the files.

That way the knowledge or at least part of it, either explicit or tacit, is definitely lost. On top of that library services only collect research projects that were actually sent to the library. These projects are of course only a tip of iceberg of the knowledge each researcher posseses. So what to do to capture and share all the knowledge that researchers have?

By prof. Dado (Dado, E., 2005) most of the knowledge resources of academic institutions »live " on hard-drives and in personal files of individual researchers. Only a part of these knowledge resources is available through traditional communication channels such as on-line libraries or databases and to some extent through non-interlinked (personal or group) web pages. As it is also true in the Slovene institute. And the possible solution to the problem is to use the portal technology.

\section{Definition of web portals from Wikipedia:}

Web portals are sites on the World Wide Web that typically provide personalized capabilities to their visitors. They are designed to use distributed applications, different numbers and types of middleware, and hardware to provide services from a number of different sources. In addition, business portals are designed to share collaboration in workplaces. A further business-driven requirement of portals is that the content be able to work on multiple platforms such as personal computers, personal digital assistants (PDAs), and cell phones.(From [http://en.wikipedia.org/wiki/Web_portal])

and also definition of Enterprise Web portals:

In the early 2000s, a major industry shift in Web portal focus has been the corporate intranet portal, or "enterprise Web«. Where expecting millions of unaffiliated users to return to a public Web portal has been something of a mediocre financial success, using a private Web portal to unite the Web communications and thinking inside a large corporation has begun to be seen by many as both a labor-saving and a money-saving technology. Some corporate analysts have predicted that corporate intranet Web portal spending will be one of the top five areas for growth in the
Internet technologies sector during the first decade of the $21^{\text {st }}$ century.

Some features of enterprise portals are:

Single touch point - the portal becomes the delivery mechanism for all business information services.

Collaboration - portal members can communicate synchronously (through chat, or messaging) or asynchronously through threaded discussion and email digests (forums) and blogs.

Content and document management - services that support the full life cycle of document creation and provides mechanisms for authoring, approval, version control, scheduled publishing, indexing and searching.

Personalization - the ability for portal members to subscribe to specific types of content and services. Users can customize the look and feel of their environment.

Integration - the connection of functions and data from multiple systems into new components/portlets.

Most enterprise portals provide single sign-on capabilities to their users. This requires a user to authenticate only once. Access control lists manage the mapping between portal content and services over the portal user base.

Enterprise portals may be referred to by the community they serve. For instance, an employee-facing portal may be described as a "Business-to-employee " portal, or B2E portal. Other enterprise portal classifications are "B2C (business-to-customer/consumer), »B2D « (business-to-dealer/ distributor), »B2B « (business-to-business/supplier), and "B2G « (business-to-government). Enterprises may develop multiple "B2x" portals based on business structure and strategic focus, but leverage a common architectural framework, reusable component libraries, and standardized project methodologies.

(From [http://en.wikipedia.org/wiki/Web_portal])

A portal can be divided into three different types: First one is called "vertical « portal - it provides access to a variety of information and services about a particular area of interest. Such portals offer information and services customized for particular audiences. The second one is "horizontal « portal, which is often referred to as »megaportal." That kind of a portal targets the entire internet community. Sites such as Lycos.com, Netscape.com and Yahoo.com, are examples of megaportals. These sites always contain search engines and provide the ability for users to personalize the page by offering various channels. Providers of megaportals hope individual users will go to their sites first so as to access the rest of the internet. Their financial models are built on a combination of advertising and »clickthrough « revenues. The last type it the university or enterprise portal, which can be either vertical-focusing on a specific application, such as human resources, accounting, or financial aid information, or horizontal-offering access to almost all the information an individual within the university needs to carry out his or her function. Authentication and access are based upon the role or roles an individual plays in the organization. Horizontal enterprise portals can be customized and personalized. If properly designed, they can replace much of the user's computer desktop.

Portals can also serve in a knowledge management function by dealing with information in an organized fashion. Like in a knowledge cycle, the portal must be able to encompass the following processes: knowledge capturing or creating, knowledge organizing, knowledge processing or sorting, knowledge sharing and using a knowledge. 
Steffen Staab (STAAB S. at al, 2001) proposes the following: Once a KM system is fully implemented in an organization, knowledge processes essentially circle around the following steps:

1. Knowledge creation and/or import, i.e. contents need to be created or converted such that they fit the conventions of the company, e.g. to the knowledge management infrastructure of the organization;

2. then knowledge items have to be captured in order to elucidate importance or interlinkage, e.g. the linkage to conventionalized vocabulary of the company;

3. retrieval of and access to knowledge satisfies the "simple « requests for knowledge by the knowledge worker;

4. typically, however, the knowledge worker will not only recall knowledge items, but will process it for further use in the context.

The Slovene institute is equipped with personal computers with Microsoft operating system and with a Microsoft Server 2000. The logical choice for the portal was the SharePoint Team Services from Microsoft. The software comes free with Microsoft Server and it is easy to install and maintain. But does it provide all the tasks for knowledge management?

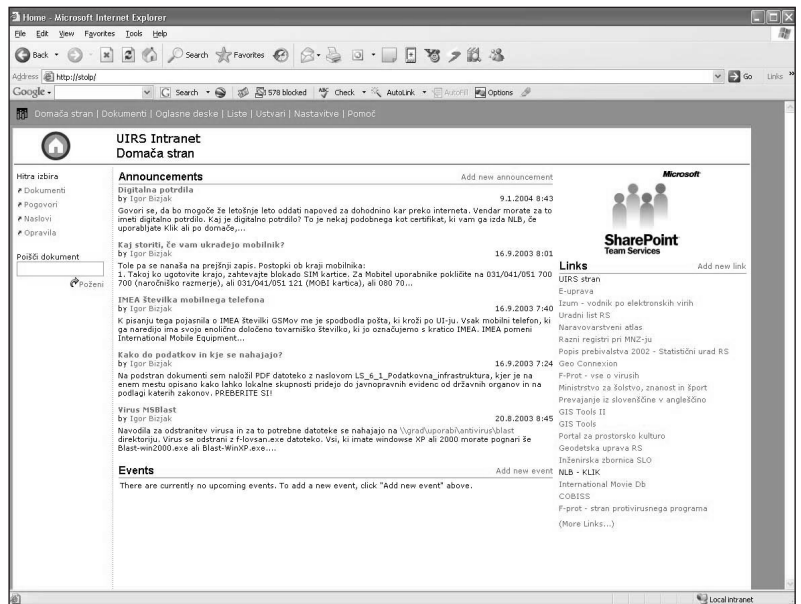

Figure 2: SharePoint Team Services (BIZJAK I., 2006)

Knowledge capturing: SharePoint Team Services provide a central repository for documents, information and ideas, and allow users to work interactively. Every user can import documents and can even make a new library for documents. Documents can be Microsoft Office files like Word, Excel or Power Point files, or just some notepad files. The same goes for picture files. It is possible to share the data from Microsoft Outlook like schedule or contacts.

Knowledge organizing and sorting: At the same time a user imports the knowledge it is also sorted, by putting the document into the right type of library. This can also be done by a third person, the knowledge manager, whose only work is to look after and care for the portal.

Knowledge sharing and usage: SharePoint Team Services are web based services, so if they are on the local intranet or internet (for instance company web pages), they are available to all users who have access to the intranet or internet. The Services also provide the way to notify the users when some data changed via e-mail. And when the event happened, user can read the new document or react on the change.

Capturing the tacit knowledge: One of the service with the SharePoint Team Services is the discussion board system. It is like newsgroup system. The users can pose questions and answers or they can comment documents. And there is another service. It is the survey service. With this service the user can make a survey for other team members. The results can be exported to Microsoft Excel and then presented in a chart form.

Basically the SharePoint Team Services provide all tasks of knowledge management for a small organization. The idea was that every computer in the Institute's internal network (intranet) uses the default page on the web browser the page of the SharePoint Team Services. So every time researchers access internet, they stumble on a default page and indirectly upon different news, reviews, documents, chat etc. on that particular page. Users can open forums to discus research projects, ideas, ask questions, upload own research projects or papers to document folders so that other researchers can use them, learn and broaden their knowledge. The SharePoint Team Services is a good tool for research teams also, because it enables them to use the services schedule tool and therefore schedule the research project, to collect data relevant to the research project in one place.

\section{Conclusions}

Knowledge is one of the main assets of every organization. And knowledge is primarily created by people. Some bring their knowledge with them into the organization, they gain knowledge in the organization and some take the knowledge with them, when they leave. It is a resonsability of an organization to secure its knowledge. And the management within the organization should be aware of that and do everything to harvest that knowledge and implement it or invest in it. All that can be achieved with the help of knowledge management, which is one of the most important principles that companies must explore nowadays and use to gain the competitive advantage, even in buildings and construction industry.

The only way to survive is to constantly adapt to the environment, constant growth and constant overtaking the competition. And that we can achieve only with knowledge and with ability of our employees to think and work better and rapidly than the employees of the competitors. (SLAK M.,2002)

The knowledge management system all by itself it is not enough. The employees makes it work. In the case of Urban Planning Institute it was presented to the researcher, but more than a few documents posted into the library and a few announcements presented, nothing happened. At the time that SharePoint Team Service was established, the researchers were not aware that it is knowledge that it's all about and not the SharePoint Team Services. So today no one is using it.

What follows? There are a few possibilities.

First, researcher should be educated or at least follow lectures on knowledge management organized for him. The 
course that would show the benefits and the possibilities of knowledge management for the Institute and for them to use it. Then the course of using the software for knowledge management system researchers would be familiarized with it. The researchers' computers would be set up in a way that the portal web page would be the default web page on entering a browser.

Secondly, the Institute administration and management should be aware of what knowledge management is and its completive advantage. The management is then motivated to encourage researchers and to move the system in motion.

And the third, the knowledge manager should be appointed to take over the system and to further educate the users and to monitor new releases, to also be able to upgrade the system with better services.

That is the least what the Slovene Institute should do to ensure the knowledge will stay in the organization and that the organization will benefit from and implement it.

Igor Bizjak, architect, Urban Planning Institute of the Republic of Slovenia, Ljubljana

E-mail:igor@uirs.si

For references, literature and web links turn to page 133.

\section{Public lectures at the Urban planning institute}

Joost Bergers is the Project Officer in the Street Scene Section of the Department of planning and transportation at the City of London. He was visiting Ljubljana in May 2007 and gave a public lecture on City of London's programme for a creation of a high quality public space. He kindly complied with our request and answered some questions after his talk.

What is the specific of the urban environments of the City of London? Which functions does it hold and what is its role within the city and in a broader context?

The City is the oldest part of London and build on the foundations of Roman Londinium. Large parts of the city have maintained their medieval street pattern and historic buildings. These historic features will maintain, but modern buildings built from 60's onwards have a shorter lifespan and today may only last 30 to 40 years. The City of London is the world's leading financial and business centre. It generates much of London's and the UK's income.

How strong is the local community in the City of London? There are approximately 7,500 residents in the City. It has the least inhabitants of all London boroughs and is also geographically the smallest. It's also called the Square Mile. Most people live in the Barbican, which is a well established community. Most obvious though is the business community. Over 300,000 people work in the City.

How would you describe the public open spaces in the City of London in general? What are their specifics in comparison with other parts of London or other bigger European cities?

Because of its historic character and premium land value there is relatively less open space than in other parts of London. Open spaces often have hard surfaces with well maintained gardens and are hidden between developments. It is really exiting to wander through the City and find these often little known places.

When and how did the Street Scene Challenge initiative start - who were the initiators and what were the initial goals?

The Street Scene Challenge started in 2000. It came into existence because it was evident that the City had neglected its public domain and had done little to it since the 60's when there was a surge in large scale office developments. The SSC was initiated by Victor Callister who realised that the lack of attention to the City streets and spaces had an adverse effect on the City as world leading finance and business centre and the communities it serves. The initial goal was to improve the public realm of the City of London.

What are the main objectives of SSC today and who are the involved parties?

The concept has developed but hasn't changed much as such. Its main objective is to create a public realm that supports the City of London as the leading financial and busi- 